\title{
Normal rate of ventricular emptying in valvular aortic stenosis ${ }^{\star}$
}

\author{
STEVEN M LEDERMAN, ARNOLD K GASH, ALFRED A BOVE†, JAMES F SPANN \\ From the Section of Cardiology, Department of Medicine, Temple University Health Sciences Center, Philadelphia, \\ Pennsylvania, USA
}

SUMmaRY The delayed upstroke of the arterial pulse in valvular aortic stenosis has been attributed, in part, to prolonged left ventricular emptying. Left ventricular emptying rate, however, has not been measured in aortic stenosis. We assessed the rate of left ventricular emptying by computer analysis of biplane cineangiograms in seven normal subjects, six patients with mild to moderate aortic stenosis, and 12 patients with severe aortic stenosis. As an indicator of delayed arterial pulse rise, $\mathrm{T}$ time index (time to half maximum aortic pressure corrected for heart rate) was measured in each group. T time index averaged $0.07 \pm 0.01$ units in normal subjects, $0.14 \pm 0.04$ units in the patients with mild to moderate aortic stenosis, and $0.13 \pm 0.05$ units in those with severe aortic stenosis. Patients with mild to moderate and severe aortic stenosis differed significantly from normal subjects. Relative emptying rates were defined as the percentage of initial systolic volume ejected divided by the percentage of systole elapsed. These relative emptying rates were determined during the first, second, and third thirds of systole in all three groups. No significant decrease in the relative rate of left ventricular emptying was noted when each group of patients with aortic stenosis was compared with the normal subjects. Neither was there slowing in the actual rate of ejection of blood in $\mathrm{ml}$ per second throughout systole. We conclude that the rate of ventricular emptying is normal in aortic stenosis and does not explain the arterial pulse delay in this disease.

Valvular aortic stenosis causes alterations in both central and peripheral arterial pressure pulses. ${ }^{1} 2$ The delayed rise of the aortic and carotid pulses is useful in identifying valvular aortic stenosis, though less accurate in predicting the degree of stenosis. Despite acceptance of these abnormal pulse characteristics as clinical features of the disease, their physiological causes are not well understood. One theory is that left ventricular ejection is prolonged because of obstruction to blood flow across the stenotic aortic valve. ${ }^{34}$ Two limitations to this view are apparent. First, the aortic pulse contour is dependent on factors such as intrinsic aortic compliance and the matching of impedance between the left ventricle and the aorta. Second, instantaneous flow of blood from the left ventricle during systole has not been examined in aortic stenosis.

We have used a computer based image analysis system to document instantaneous flow during left ventricular ejection using 60 frames/second analysis of biplane ventriculograms. The relation between left ventricular emptying and aortic pressure pulse was

* This study was supported in part by funds from NIH grants.

† Established Investigator of the American Heart Association.

Received for publication 10 February 1981 then assessed in patients with mild to moderate and severe valvular aortic stenosis and compared with a group of normal subjects.

\section{Subjects and Methods}

PATIENTS

Seven normals and 18 patients with aortic stenosis were studied. The aortic stenosis patients were divided into two groups on the basis of gradient and valve orifice area. Six patients had mild to moderate disease and 12 patients had severe disease.

HAEMODYNAMIC AND ANGIOGRAPHIC DATA AND PRESSURE PULSE ANALYSIS

All patients were studied in the cardiac catheterisation laboratory of Temple Univeristy Hospital. All catheterisations were performed because of clinical indications. The normal group was studied because of atypical chest pain and each individual in this group had normal left ventricular performance, coronary arteries, and haemodynamics within the limits accepted as normal for our laboratory.

Aortic pressure was measured using a fluid filled No. 7 French NIH catheter passed retrogradely from 
the brachial artery, or a pig tail catheter passed percutaneously from the femoral artery into the central aorta. A Statham P23DB strain guage was used and tracings were made on an Electronics for Medicine DR8 multi-channel recorder. Paper speeds of 50 to $100 \mathrm{~mm} / \mathrm{s}$ were used in the analysis of recordings. Aortic valve gradients were measured from simultaneous left ventricular and brachial artery pressure recordings. Valve areas were calculated according to the method of Gorlin and Gorlin. Cardiac output was measured by the dye dilution method. Biplane left ventricular cineangiograms were obtained in the 30 degree right anterior oblique and 60 degree left anterior oblique projections.

To assess the rate of rise of aortic pressure pulse, the $\mathrm{T}$ time index as described by Tavel $^{5}$ was determined as the time to one-half peak aortic pressure divided by the preceding $R R$ interval.

\section{VENTRICULOGRAPHIC ANALYSIS}

The computer analysis of biplane ventriculograms used in our laboratory has been described previously. ${ }^{6}$ Biplane 60 frames $/ \mathrm{s} 35 \mathrm{~mm}$ cineventriculograms are analysed using a computer-based digitising table which converts ventriculographic frame images into digital form and stores the digital information on magnetic tape. These data are then used to compute ventricular volume and display curves of ventricular volume versus time at $1 / 60$ th second intervals throughout one complete heart cycle. Both systole and diastole can be analysed in this fashion. Ventriculographic analysis was confined to systole for purposes of the present study.

Initial systolic volume was defined as the maximal ventricular volume and end-systolic volume as the minimal ventricular volume. By use of computer analysis, volume versus time curves could be displayed in two ways. First, actual ventriculographic volume could be plotted as a function of actual systolic time, as shown in the normal sample curve in Fig. 1a. The second mode of data display was standardised volume versus standardised time developed as follows: ventricular volume at each 1/60th second was expressed as a percentage of initial systolic volume and systolic time elapsed as a percentage of total systolic time. Fig. $1 b$ illustrates the standardised curve obtained from the actual volumetime data in Fig. 1a. At $0 \%$ systolic time, ventricular volume is $100 \%$ initial systolic volume (or $150 \mathrm{ml}$ ). At $100 \%$ systolic time (end-systole or $0.370 \mathrm{~s}$ ) the ventricle contains $33 \%$ of its initial systolic volume (or $50 \mathrm{ml}$ ). Furthermore, the change in percentage of initial systolic volume as systole proceeds from $0 \%$ to $100 \%$ of systoic time is the ejection fraction, so that at end-systole the percentage of initial systolic volume remaining in the ventricle equals $100 \%$-ejection fraction.

The standardised display of volume versus time has several advantages. First, it permits comparisons of ventricular emptying to be made between groups of patients with slightly different initial systolic volumes and heart rates. Second, ventricular emptying can be analysed in isolated segments of systole. In this study we examined the relative rates of ventricular emptying during the initial, middle, and final thirds of systole. This relative rate of ventricular emptying was defined as the percentage of initial systolic volume ejected during a particular segment of systole, or the change

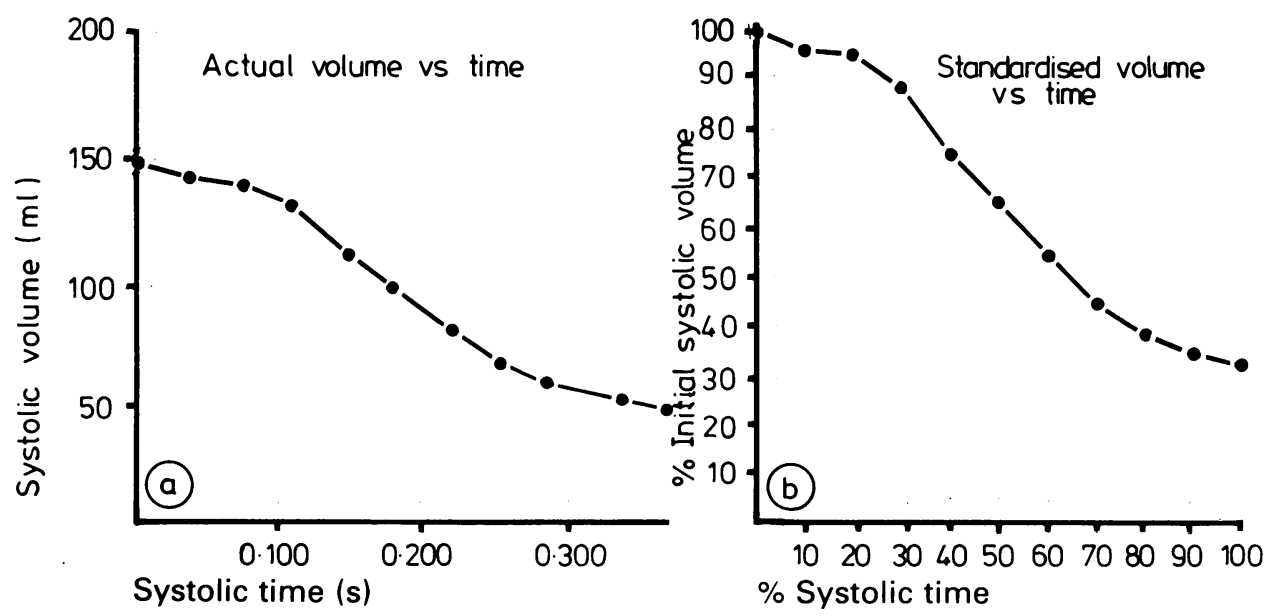

Fig. 1 (a) Ventricular emptying curve from a normal subject. Ventriculographic volume is expressed as a function of systolic time elapsed from end-diastole to end-systole $(b)$ Standardised ventricular emptying curve from the same normal subject. The percentage of initial systolic (or end-diastolic) volume contained in the ventricle is expressed as a function of the percentage of systolic time elapsed. 
in percentage of initial systolic volume present in the ventricle divided by $33 \%$ (since systole was divided into thirds). Since the relative rate of ventricular emptying is derived by dividing percentage by percentage, it is a unitless value.

In addition to the relative rate of ventricular emptying, actual ventricular emptying rate $(\mathrm{dV} / \mathrm{dt}$ in $\mathrm{ml} / \mathrm{s}$ ) was also computed. This quantity is simply stroke volume divided by total systolic time and represents the rate at which blood leaves the ventricle over an entire systole.

\section{STATISTICAL ANALYSIS}

Comparisons between normal subjects and each group of patients with aortic stenosis were made using analysis of variance. Specific data analysed were relative emptying rates for the first, second, and third portions of systole, actual emptying rates in $\mathrm{ml}$ per second for total systole, systolic time, ejection fraction, stroke volume, initial systolic volume, and routine clinical and haemodynamic variables. $T$ time index was analysed by two-tailed $t$ test for unpaired groups.

\section{Results}

Fourteen of the 18 patients with aortic stenosis had isolated aortic stenosis without either aortic or mitral regurgitation. Three patients had concomitant trivial aortic regurgitation and one patient also had trivial mitral regurgitation. None of the subjects had left bundle-branch block, which might slow the rate of left ventricular depolarisation. Average haemodynamic data for each group are shown in Table 1.

No significant differences in heart rate or enddiastolic pressure were noted in the three groups. The cardiac index was lower in the patients with severe

Table 1 Clinical and haemodynamic data for three patient groups

\begin{tabular}{lccc}
\hline & $\begin{array}{c}\text { Normal } \\
\text { subjects }\end{array}$ & $\begin{array}{c}\text { Mild to moderate } \\
\text { aortic stenosis }\end{array}$ & $\begin{array}{c}\text { Severe } \\
\text { aortic stenosis }\end{array}$ \\
\hline $\begin{array}{l}\text { Age } \\
\text { (y) }\end{array}$ & $45 \pm 5$ & $47 \pm 9$ & $63 \pm 3$ \\
$\begin{array}{l}\text { Heart rate } \\
\text { (beats/min) }\end{array}$ & $73 \pm 3$ & $77 \pm 5$ & $70 \pm 4$ \\
$\begin{array}{l}\text { Cardiac index } \\
\left(\text { /min per m }{ }^{2}\right)\end{array}$ & $2 \cdot 4 \pm 0 \cdot 2$ & $2 \cdot 9 \pm 0 \cdot 4$ & $2 \cdot 1 \pm 0 \cdot 1$ \\
$\begin{array}{l}\text { LVEDP } \\
\text { (mm Hg) }\end{array}$ & $9 \pm 1$ & $11 \pm 2$ & $14 \pm 2$ \\
$\begin{array}{l}\text { Mean gradient } \\
\text { (mm Hg) }\end{array}$ & - & $32 \pm 8$ & $62 \pm 4$ \\
$\begin{array}{l}\text { Valve area } \\
\left(\mathrm{cm}^{2}\right)\end{array}$ & - & $1 \cdot 4 \pm 0 \cdot 4$ & $0 \cdot 5 \pm 0 \cdot 1$ \\
\hline
\end{tabular}

Data are means \pm standard errors of the means.

LVEDP, left ventricular end-diastolic pressure. aortic stenosis $(p<0.05)$ than in those with mild-tomoderate stenosis, but not when compared with that in the normal subjects. Obviously, mean gradient $(p<0.01)$ and valve area $(p<0.01)$ were significantly different between the two groups with aortic stenosis. The mean age of the group with severe aortic stenosis was significantly higher than that of the normal subjects $(\mathrm{p}<0.05)$.

$\mathrm{T}$ time indices were determined in six normal subjects and in 14 of the patients with aortic stenosis patients (Fig. 2). The average in the normal group was $0.07 \pm 0.01$ units. The maximum $\mathrm{T}$ time index observed in the normal subjects was 0.08 units. $T$ time index was increased significantly in the patients with mild to moderate aortic stenosis $([0 \cdot 14 \pm 0.04$ units] compared with the normal subjects $[\mathrm{p}<0.002]$ and the patients with severe aortic stenosis $[0.13 \pm$ 0.05 ] compared with normal subjects $[p<0.02])$. It can be seen that 12 of 14 patients with aortic stenosis had $\mathrm{T}$ time indices beyond the range of the normal subjects. Two patients with severe aortic stenosis, however, had $\mathrm{T}$ time indices at the upper limit of normal.

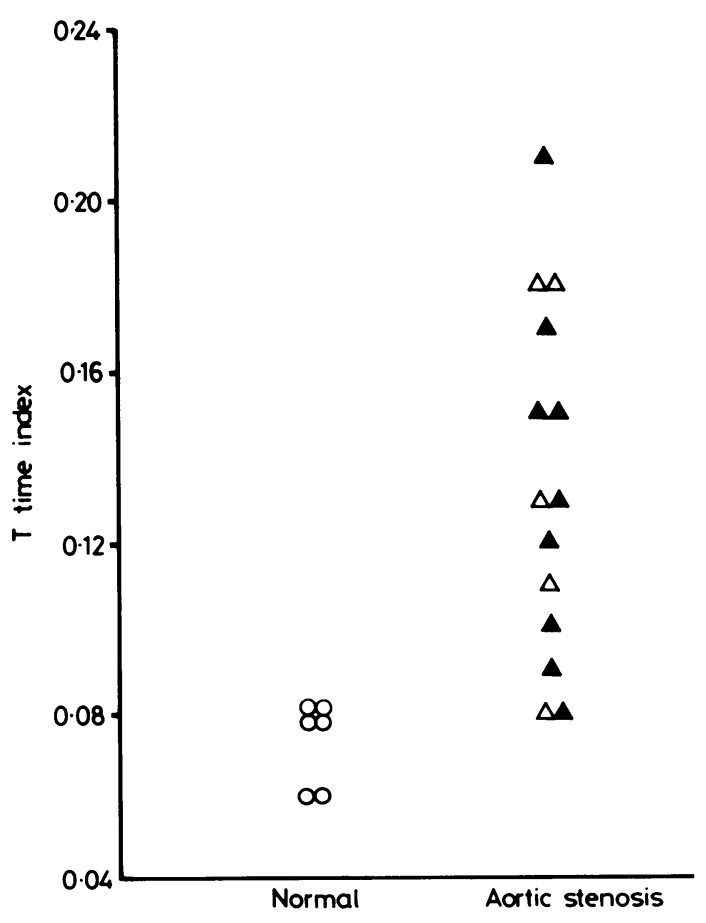

Fig. 2 T time indices of normals and patients with aortic stenosis. Closed triangles represent patients with severe aortic stenosis. Open triangles represent patients with mild to moderate aortic stenosis. 
Table 2 Ventriculographic volume and emptying analysis for the three patient groups

\begin{tabular}{|c|c|c|c|}
\hline & $\begin{array}{l}\text { Normal } \\
\text { subjects }\end{array}$ & $\begin{array}{l}\text { Mild to moderate } \\
\text { aortic stenosis }\end{array}$ & $\begin{array}{c}\text { Severe } \\
\text { aortic stenosis }\end{array}$ \\
\hline $\begin{array}{l}\text { ISV } \\
\text { (ml) }\end{array}$ & $176 \pm 11$ & $197 \pm 36$ & $244 \pm 24$ \\
\hline $\begin{array}{l}\text { SV } \\
(\mathrm{ml})\end{array}$ & $93 \pm 14$ & $111 \pm 16$ & $142 \pm 13$ \\
\hline EF & $0.61 \pm 0.04$ & $0.60 \pm 0.06$ & $0.60 \pm 0.04$ \\
\hline $\begin{array}{l}\text { Systolic time } \\
\text { (ms) }\end{array}$ & $324 \pm 26$ & $314 \pm 17$ & $339 \pm 13$ \\
\hline $\mathrm{dV} / \mathrm{dt}(\mathrm{ml} / \mathrm{s})$ & $333 \pm 26$ & $354 \pm 50$ & $414 \pm 30$ \\
\hline VER $_{1}$ & $0.67 \pm 0.06$ & $0.53 \pm 0.12$ & $0.54 \pm 0.05$ \\
\hline $\mathrm{VER}_{2}$ & $0.79 \pm 0.08$ & $0.72 \pm 0.08$ & $0.76 \pm 0.08$ \\
\hline $\mathrm{VER}_{3}$ & $0.38 \pm 0.06$ & $0.54 \pm 0.08$ & $0.53 \pm 0.06$ \\
\hline
\end{tabular}

Data are means \pm standard errors of the means; $\mathrm{dV} / \mathrm{dt}$, ventricular emptying rate; EF, ejection fraction; ISV, initial systolic or enddiastolic volume; $S V$, stroke volume; $V_{E R}$, relative ventricular emptying rate during first third of systole; $\mathrm{VER}_{2}$, relative ventricular emptying rate during second third of systole; $\mathrm{VER}_{3}$, relative ventricular emptying rate during last third of systole.

Table 2 shows the actual time and volume indices and actual $\mathrm{dV} / \mathrm{dt}$ in the three patient groups. The duration of systole, ejection fraction, ventricular emptying rate, and relative emptying rates for the first, second, and final thirds of systole in the three groups were not statistically different. Initial systolic volume and stroke volume were significantly greater only in the groups with severe aortic stenosis compared with normal subjects $(p<0.05$ and $p<0.05$, respectively).

Because of the difference in mean age between the patients with severe aortic stenosis and the normal

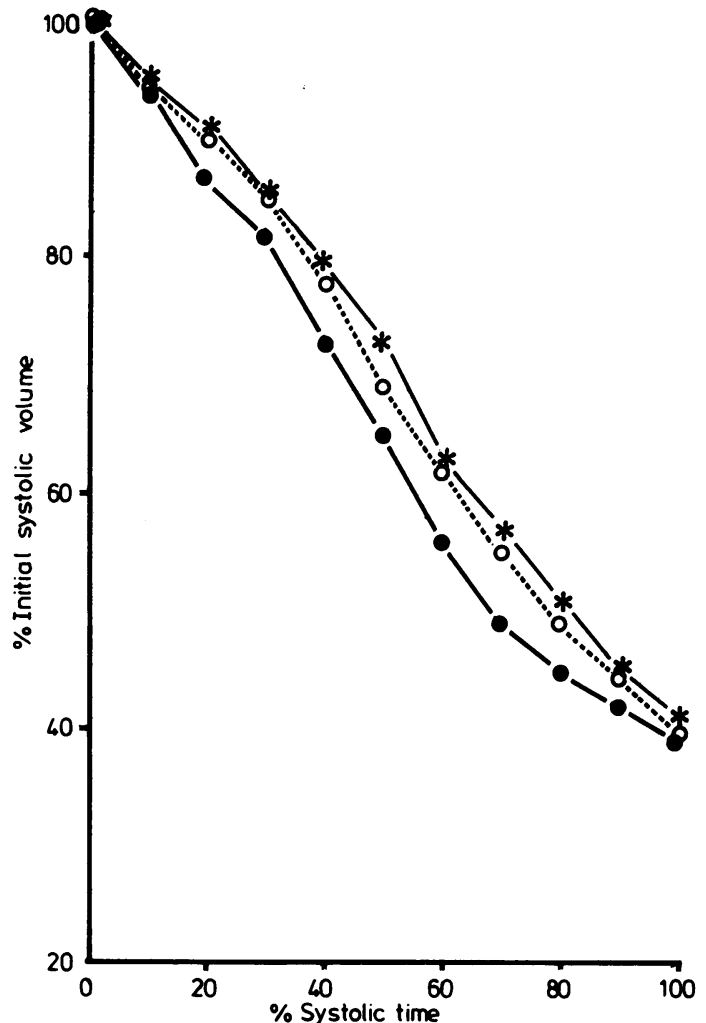

Fig. 4 Composite standardised ventricular emptying curves of the entire group of normal subjects (closed circles), the group with mild to moderate aortic stenosis (stars), and the group with severe aortic stenosis (open circles). The patterns of ventricular emptying among the three groups are similar.

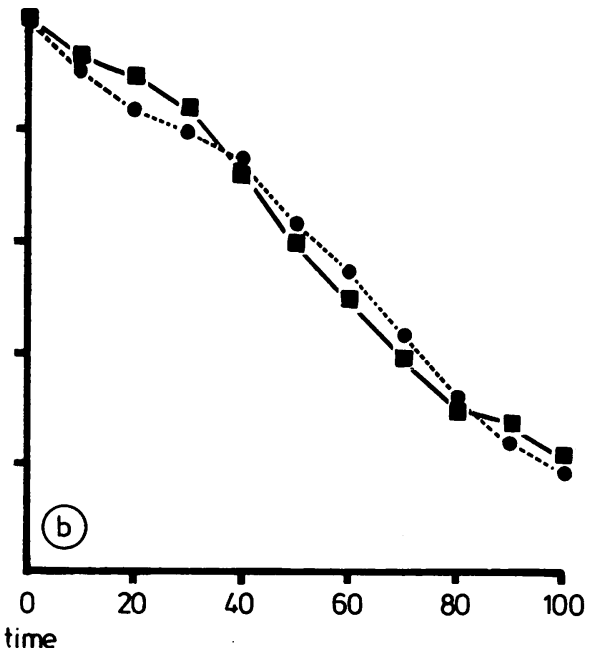

Fig. 3 (a) Standardised ventricular emptying curve of a 49-year-old normal subject (closed circles), and a 48-year-old patient with severe aortic stenosis (closed squares). (b) Standardised ventricular emptying curve of a 61-year-old normal subject (closed circles) and a 64-year-old patient with severe aortic stenosis (closed squares). 
subjects, we felt it important to exclude age as a factor in ventricular emptying rate. Fig. $3 \mathrm{a}$ and $\mathrm{b}$ display the standardised ventricular emptying curves of two patient pairs of similar ages, each pair comprising one patient with severe aortic stenosis and one normal patient. It is obvious that the patterns of ventricular emptying are similar.

Fig. 4 shows composite standardised volume versus time curves for each patient group as a whole. The patterns of ventricular emptying are similar.

\section{Discussion}

Abnormalities of the contour and timing characteristics of the arterial pulse are recognised clinical features of valvular aortic stenosis. Qualitative findings include a prolonged upstroke, prominent anacrotic shoulder, and palpable carotid shudder. ${ }^{12}$ Because of the pulse alterations unique to valvular aortic stenosis, numerous quantitative indices based on the externally recorded carotid pulse and internally recorded aortic pulse have been devised. These indices purport to, first, identify patients with aortic stenosis, and second, estimate the severity of valvular obstruction. The brachial or carotid upstroke time is prolonged in most patients but correlates poorly with the severity of aortic stenosis. ${ }^{2} 3$ Both aortic $\mathrm{dP} / \mathrm{dt}^{7}$ and externally measured maximum carotid $\mathrm{dP} / \mathrm{dt}^{8}$ are reduced in aortic stenosis, but these measurements correlate poorly with gradient or valve area. A prolonged left ventricular ejection time corrected for heart rate has been found to correlate with the presence of valvular obstruction but suffers the same limitations as upstroke time and slope in assessing its severity. ${ }^{2910}$ By combining corrected left ventricular ejection time with the maximum rate of rise of the carotid pulse and the timing of the peak of the systolic murmur, Bonner et al. ${ }^{10}$ have been able to predict the severity of aortic stenosis more accurately than by any one of these indices used alone. In addition to these systolic pulse indices, the $T$ time index (that is, the time to half the peak of aortic or carotid systolic pulse corrected for heart rate) appears reliable in identifying aortic stenosis. ${ }^{5}$

The measurements used to assess the aortic pressure pulse in aortic stenosis have been based in part on the assumption that the left ventricle empties more slowly than normal, but this fact has not been substantiated. Though the present study confirms that the $\mathrm{T}$ time index is increased in patients with moderate and severe aortic stenosis compared with normal subjects, analysis of the rate of change of ventriculographic volume in systole has shown no delay in left ventricular emptying, which we conclude therefore is not the cause of the slow rise of aortic pressure in aortic stenosis.
To determine the systolic emptying characteristics of the left ventricle it is important to construct a volume versus time curve with frequent enough samples to represent accurately each portion of systole to be examined. We have previously shown that sampling left ventricular volume at 60 samples per second provides enough data to reproduce accurately the ventricular volume curve. ${ }^{6}$ Though the emptying pattern of the ventricle can be examined by use of an actual volume versus time curve, we have chosen to construct a standardised curve of ventricular emptying in order to describe the ejection phase more completely. This curve takes into account the initial systolic (end-diastolic) volume variation among patients, and the variation in systolic time caused by different heart rates. The resultant curves express systolic ventricular emptying as percentage of initial systolic volume versus percentage of total systolic time. We have also computed a relative ventricular emptying rate by examining the change in percentage of initial systolic volume over isolated segments of systole.

One could argue that the standardisation process involving groups of patients might create mathematical bias. Examination of the data shows this not to be the case. The actual rate of ventricular emptying over total systole is a function of stroke volume and systolic time. Though there may have been minor variations in heart rate from patient to patient, actual durations of systole were similar. Given similar systolic times, any differences in total emptying rates would then need to be related to differences in stroke volume. Since stroke volume in the group aortic stenosis was larger than in the normal subjects a larger $\mathrm{dV} / \mathrm{dt}$ would be expected in this group. Though $\mathrm{dV} / \mathrm{dt}$ was not statistically larger than normal, the values tended to be higher. This means that the patients with aortic stenosis ejected a similar or slightly greater volume of blood during the same systolic time as normals. Since the standardisation process expressed volume changes as a percentage of initial systolic volume, instantaneous ventricular volume is divided by initial systolic volume for each systole examined in each patient group. Since the patients with severe aortic stenosis had larger initial systolic volumes, any bias introduced by standardisation would have resulted in an apparent decrease in relative ventricular emptying rate in this group. In fact, no such decrease was observed during any third of systole.

Studies of the relation between aortic and left ventricular pressure and flow as well as studies of impedance changes within the arterial tree suggest that the shaping of the aortic pressure pulse is complex. There exists no simple explanation for the slow-rising pulse of aortic stenosis. Mason et al. ${ }^{11}$ 
have shown that the peak of left ventricular pressure occurs relatively early and the bulk of the transvalvular gradient occurs in the first half of systole despite the late peaking aortic pressure in aortic stenosis. They found the reverse to be true in hypertrophic obstructive cardiomyopahty, a condition that has different arterial pulse characteristics. $O^{\prime}$ Rourke $^{1213}$ has shown that when a large vessel is constricted by a flow probe, kinetic pressure (or the difference between impact and lateral pressure) is increased. This disparity between forward and sideto-side pressure is proportional to the degree of constriction. Recently Pouleur et al. ${ }^{14}$ have shown that venous return is an important factor in modifying aortic impedance.

It is possible that energy loss from fluid friction or turbulence across the stenosis contributes to alterations in aortic pressure pulse. If one considers total energy in the blood leaving the ventricle, there will be several components which are best related by the Bernoulli ${ }^{15}$ equation. If height differences are neglected, the energy is contained in velocity and pressure components. Across the stenosis the pressure component is reduced because of frictional or turbulent energy loss in the narrowed stream. The velocity component, however, should not change, for since the same volume of blood must move through the left ventricular outflow tract and ascending aorta (minus a small systolic coronary flow) distal to the stenosis, and since the diameter of the flow conduit at those two locations is nearly the same, the velocity component (flow/area) will be unchanged.

Gorlin and Gorlin's study ${ }^{16}$ showed that the pressure drop across the stenosis accounts for the total stenotic resistance of the narrowed valve; thus there is no further energy loss with which to explain the slow rising aortic pulse. A more likely explanation lies in an altered impedance at the valve or in the coupling of impedance between ventricle and aorta.

Systolic arterial pulse indices other than $T$ time index were not measured in our present study, since the $T$ time index is related primarily to the rate of rise of central arterial pressure pulse. Therefore, we cannot draw conclusions concerning the relation between ventricular emptying measured by left ventricular volume analysis and "left ventricular ejection time" measured by direct or indirect pressure pulse recordings. We can conclude, however, that the slow rise in the central arterial pressure pulse in valvular aortic stenosis is not a result of a decrease in the rate at which blood leaves the left ventricle.

\section{References}

1 Wood P. Aortic stenosis. Am $\mathcal{F}$ Cardiol 1958; I: 553-71.

2 Robinson B. The carotid pulse I: Diagnosis of aortic stenosis by external recordings. Br Heart $\mathcal{F}$ 1962; 25: $51-60$.

3 Hancock EW, Fleming PR. Aortic stenosis. $Q \mathcal{J}$ Med 1960; 29: 209-34.

4 Epstein EJ, Coulshed N. Assessment of aortic stenosis from the external carotid pulse wave. Br Heart $f$ 1964; 26: 84-96.

5 Tavel ME. Clinical phonocardiography and external pulse recording. 3rd ed. Chicago \& London: Year Book Medical Publishers, 1978.

6 Bove AA, Kreulen TH, Spann JF. Computer analysis of left ventricular dynamic geometry in man. Am $\mathcal{F}$ Cardiol 1978; 41: 1239-48.

7 Arani DT, Carlton RA. Assessment of aortic valvular stenosis from the aortic pressure pulse. Circulation 1967; 36: 30-5.

8 Lyle DP, Bancroft WH Jr, Tucker M, Eddleman EE Jr. Slopes of the carotid pulse wave in normal subjects, aortic valvular diseases, and hypertrophic subaortic stenosis. Circulation 1971; 43: 374-81.

9 Parisi AF, Salzman H, Schechter E. Systolic time intervals in severe aortic valve disease changes with surgery and hemodynamic correlations. Circulation 1971; 44: 539-47.

10 Bonner AJ Jr, Sacks HN, Tavel ME. Assessing the severity of aortic stenosis by phonocardiography and external carotid pulse recording. Circulation 1973; 48: 247-52.

11 Mason DT, Cohen LS, Spann JF, Demaria AN, Joye JA, Miller RR. Diagnostic value of configuration of left ventricular outflow pressure gradient in differentiating hypertrophic obstructive cardiomyopathy from discrete types of aortic stenosis. Br Heart $\mathcal{f}$ 1978; 40: 315-19.

12 O'Rourke MF. Impact pressure, lateral pressure, and impedance in the proximal aorta and pulmonary artery. $\mathcal{F}$ Appl Physiol 1968; 25: 533-41.

13 O'Rourke MF. The arterial pulse in health and disease. Am Heart F 1971; 82: 687-702.

14 Pouleur H, Covell JW, Ross J. Effects of alterations in aortic input impedance on the force-velocity-length relationship in the intact canine heart. Circ Res 1979; 45: 126-36.

15 Sears FW, Zemansky MW. University physics. 3rd ed. Reading, Massachusetts: Addison-Wesley, 1963; 311-3.

16 Gorlin R, Gorlin SG. Hydraulic formula for calculation of the area of the stenotic mitral valve, other cardiac valves and central circulatory shunts. 1. Am Heart $\mathcal{f}$ 1951; 41: 1-29.

Requests for reprints to Dr Arnold $\mathrm{K}$ Cash, Section of Cardiology, Temple University Health Sciences Center, 3401 North Broad Street, Philadelphia, Pennsylvania 19140, USA. 